\title{
Centro de excelência e ginástica artística feminina: A perspectiva dos técnicos brasileiros
}

\author{
Myrian Nunomura ${ }^{1,2}$ \\ Mauricio Santos Oliveira ${ }^{3}$ \\ ${ }^{1}$ Escola de Educação Física e Esporte de Ribeirão Preto, USP - \\ Universidade de São Paulo, Ribeirão Preto, SP, Brasil \\ ${ }^{2}$ Equipe Universitária de Estudos em Ginástica (EUNEGI), USP . \\ Universidade de São Paulo, São Paulo, SP, Brasil \\ ${ }^{3}$ Programa de Pós Graduação da Escola de Educação Física e Esporte, \\ USP - Universidade de São Paulo
}

\begin{abstract}
Resumo: Durante o período de 2001-2008, a Confederação Brasileira de Ginástica implementou o sistema de seleção permanente concentrada no Centro de Treinamento (CT) de Curitiba. Através de um formato semelhante às escolas-internato esportivas da antiga União Soviética, as ginastas passaram a treinar juntas sob o comando de um renomado técnico estrangeiro. Este artigo visa apresentar e discutir 0 contexto deste CT e o sistema de seleção permanente da ginástica artística feminina (GAF) brasileira, a partir da opinião dos técnicos que desenvolvem a modalidade no país. Procedemos a um estudo de campo e entrevistamos 34 treinadores de 29 instituições. Dentre os aspectos positivos da seleção permanente, os sujeitos relacionaram principalmente a infraestrutura disponível às ginastas. Sobre os aspectos negativos, foram citados problemas relacionados ao rigor do treinamento, à polarização e a consequente monopolização das atletas, o que revela que, provavelmente, não houve uma adaptação do modelo soviético às características da GAF desenvolvida no Brasil.
\end{abstract}

Palavras-chave: centro de treinamento; técnicos estrangeiros; preparação centralizada.

\section{Centre of excellence for women artistic gymnastics:} The Brazilian coaches` perspective

\begin{abstract}
During the period of 2001 and 2008, the Brazilian Gymnastics Confederation implemented the gymnasts training boarding center system at the Curitiba Training Center (TC). Using the former Soviet Union model of sports boarding schools, the Brazilian gymnasts started to train together under the supervision of a technical team led by a renowned foreign coach. This article aims to discuss the context of the TC and the system of centralized preparation of the Brazilian women artistic gymnastics (WAG) showing the point of view of the coaches. We conducted a field survey and we interviewed 34 coaches of 29 sport institutions. Among the positive aspects, the coaches reported about the better infrastructure available to the gymnasts. The negative aspects refer to the problems regarding rigorous training, the polarization and the consequent monopolization of athletes showing lack of adaptation of the Soviet model to the WAG characteristics developed in Brazil.
\end{abstract}

Keywords: training center; foreign coaches; centralized preparation.

\section{Introdução}

$\mathrm{Na}$ esfera internacional da ginástica artística (GA), os Centros de Treinamento (CT) de Deva, na Romênia, e Round Lake, na Rússia, são sinônimos de sucesso há décadas e se tornaram referências mundiais na formação de grandes nomes da ginástica, dentre eles: a romena Nadia Comaneci, detentora da primeira nota 10 na história dos Jogos Olímpicos, e o bielorrusso Vitaly Scherbo, maior medalhista de ouro nos Jogos Olímpicos de Barcelona.

Poderíamos destacar outros nomes consagrados da GA que se desenvolveram nestes dois CT que serviram de modelo para outros países, como: Espanha, China, Cuba e, mais recentemente, o Brasil.

Nestes locais, os ginastas treinam em regime de internato num sistema de concentração permanente. $\mathrm{Na}$ antiga União Soviética, Arkaev e Suchilin (2004) relatam que os ginastas da equipe nacional permaneciam concentrados por volta de 250 dias ao ano. Nos demais, os atletas estavam envolvidos em competições ou em treinamentos nos centros regionais e/ou locais.

Além de Round Lake, a equipe da extinta União Soviética dispunha de outros dois centros: 
Lower Esher, perto do Mar Negro, e Tsakhkdzor localizado próximo à Armênia numa região montanhosa com 1.980 metros de altitude. Essa infraestrutura disponível para os treinamentos foi primordial para a hegemonia dos resultados obtidos pela equipe soviética a partir da década de 70 até a sua dissolução. De acordo com Smoleuskiy e Gaverdouskiy (1996, p. 323), "los éxitos de la gimnasia soviética se relacionan directamente con la centralización de la preparación, teniendo en cuenta el trabajo de escuelas-internatos especializados".

Segundo Arkaev e Suchilin (2004), estas escolas esportivas eram constituídas por um ginásio específico para a prática de $\mathrm{GA}$, uma área de reabilitação e higiene (chuveiros, sauna, piscina, sala de massagem, etc.) e uma infraestrutura similar a um hotel (quartos, sala de descanso e refeitórios). Características semelhantes podem ser observadas no CT de Deva (REPORTER SPECIAL: GIMNASTELE, 2008; THE SECRET OF DEVA, 2007), no CT na China (SUEÑOS OLIMPICOS, 2006) e no CT de Madrid na Espanha (ESCUELA DE DEPORTES: GIMNASIA ARTÍSTICA FEMININA, 2001).

O conceito básico dessa preparação centralizada está fundamentado no desenvolvimento de um grupo de ginastas com potencial relativamente semelhante e cujo objetivo é aplicar métodos de treinamento intensivos, amparados por uma estrutura de ponta, que permita um controle mais eficiente dos treinos e dos aspectos médicos e psicológicos que permeiam a formação de um atleta da classe mundial (SMOLEUSKIY; GAVERDOUSKIY, 1996).

No Brasil, com o apoio do Comitê Olímpico Brasileiro (COB), a Confederação Brasileira de Ginástica (CBG) iniciou o planejamento, em 1995, de um CT de excelência para a prática e 0 treinamento da GA na cidade de Curitiba, cuja execução iniciou-se em 1997. Dois anos depois, a CBG contratou uma técnica estrangeira para comandar o projeto (CONFEF, 2004). Além do apoio do COB, o governo do Estado do Paraná forneceu o local no qual foi estabelecida a antiga sede administrativa da CBG e onde estava localizado o CT.

Dois anos após a chegada da técnica estrangeira, outros dois treinadores vieram completar a comissão técnica da equipe brasileira e iniciaram a seleção permanente de GAF em regime de concentração.
Ao longo de dois ciclos Olímpicos, a seleção permanente feminina obteve os melhores resultados da história e se classificou entre as 8 melhores equipes do mundo nos campeonatos mundiais ocorridos durante este período. Individualmente, Daiane dos Santos foi campeã na prova de solo no mundial de Anaheim, em 2003, e Jade Barbosa obteve o terceiro lugar no individual geral no mundial de Stuttgart em $2007^{1}$.

O $\underline{\text { COB }}$ (2006a) acredita que tanto o CT da GAF quanto os demais centros de outras modalidades esportivas foram essenciais na formação e na consolidação dos atletas brasileiros e, nas palavras de José Roberto Perillier, então gerente geral do Departamento Técnico do COB,

Os centros proporcionam aos atletas e aos treinadores uma melhor estrutura de trabalho. Através de uma centralização das atividades de treinamento e de uma convivência mais harmoniosa, promovem uma integração das equipes. O relacionamento entre os atletas e as comissões técnicas cresce, assim como o comprometimento do grupo em busca dos seus objetivos ( $\underline{\mathrm{COB}}, 2006 \mathrm{a}$, p. 6).

O grande sucesso competitivo da GAF, em que se destacam as medalhas conquistadas nos campeonatos mundiais e as duas classificações Olímpicas da equipe brasileira em 2004 e 2008, foram atribuídas à infraestrutura do CT e à implementação do programa centralizado da equipe. Mas, constatamos alguns problemas ocasionados por este sistema importado do modelo soviético, pois, ele pareceu não ter sido adaptado às características da GA no Brasil, entre elas o modelo clubístico de formação esportiva.

Problemas relacionados à rigidez do treinamento, ao overtraining e ao desenvolvimento não equitativo da modalidade nas diferentes regiões do país são algumas das críticas que emergiram durante e, principalmente, após o término do ciclo Olímpico 2005-2008 que coincidiu, também, com 0 fim do regime de concentração da seleção.

Para abordar estas questões supracitadas, o objetivo do presente artigo é analisar os aspectos positivos e negativos do CT de Curitiba e do regime de treinamento em concentração da seleção permanente através de uma pesquisa de campo. O tema, que foi amplamente discutido na

\footnotetext{
${ }^{1}$ Não contabilizamos a medalha de prata de Daniele Hypólito no mundial de Ghent, pois a ginasta não fazia parte do regime de concentração da seleção na ocasião.
} 
mídia esportiva nacional, não recebeu a mesma atenção do meio acadêmico. Da mesma forma, os técnicos que formavam as ginastas potenciais para a seleção não tiveram a oportunidade de expressar e registrar seu posicionamento sobre a situação vigente naquele período.

\section{O modelo brasileiro de seleção permanente}

Entre os anos de 1999 e 2001, uma treinadora estrangeira foi contratada para compor o corpo técnico da seleção brasileira. Ela foi responsável por colocar em prática um sistema de trabalho que preparou e direcionou o caminho para a abordagem de treinamento centralizado ( $\underline{\mathrm{COB}}$, 2003).

Posteriormente, o conceito brasileiro de seleção permanente foi iniciado com a chegada de outros dois técnicos estrangeiros ao Brasil. No currículo de trabalho desses treinadores constam grandes nomes da GAF internacional, entre os quais: medalhistas em competições da Europa, campeonatos mundiais e Jogos Olímpicos.

A partir de 2001, as melhores ginastas do Brasil passaram a treinar juntas em regime de concentração no CT da modalidade em Curitiba. Apenas as meninas que residiam com suas famílias na cidade voltavam para os seus respectivos lares após a longa jornada no ginásio que durava, em média, sete horas diárias, de segunda a sábado.

O treinamento concentrado trouxe uniformidade à equipe e contribuiu para a rápida ascensão da GA no Brasil, principalmente, na categoria feminina, pois foi o setor em que o projeto foi desenvolvido com mais recursos e antecedência no seu planejamento e na implementação. Somente em 2003 o projeto foi ampliado para contemplar a categoria masculina visando à preparação dos ginastas para os Jogos Pan-Americanos de Santo Domingos, na República Dominicana. Para tanto, contratou-se outro técnico estrangeiro.

Diferentemente do setor feminino, a CBG não investiu na construção de um centro específico para a GA masculina e as mudanças constantes no corpo técnico dificultaram o maior sucesso que ficou restrito, principalmente, às competições individuais (OLIVEIRA, 2010). A seleção permanente masculina foi encerrada em janeiro de 2007.
No Quadro 1, podemos acompanhar os resultados da equipe brasileira feminina e masculina nas últimas cinco edições do Campeonato Mundial, antes e durante o período da seleção permanente concentrada em Curitiba.

Quadro 1. Classificação das equipes brasileiras nos campeonatos mundiais entre os anos de 1999 e 2007.

\begin{tabular}{|c|c|c|c|c|c|}
\hline Ano & 1999 & 2001 & 2003 & 2006 & 2007 \\
\hline Feminino & $18^{\circ}$ & $11^{\circ}$ & $8^{\circ}$ & $7^{\circ}$ & $5^{\circ}$ \\
\hline Masculino & $*$ & $23^{\circ}$ & $19^{\circ}$ & $18^{\circ}$ & $17^{\circ}$ \\
\hline
\end{tabular}

* O Brasil não enviou uma equipe completa para a disputa no masculino.

Segundo o $\underline{\text { COB }}$ (2003), no período anterior à seleção permanente, a preparação das equipes não ocorria com regularidade. Os ginastas só se reuniam no aeroporto momentos antes do embarque para as competições e poucos dispunham de recursos suficientes para a sua formação esportiva nos clubes.

No caso do setor feminino, a criação da equipe permanente em regime de concentração, dentro dos moldes internacionais, foi fundamental ao proporcionar às ginastas infraestrutura e corpo técnico experiente e de renome internacional.

Com uma área de 4,5 mil $\mathrm{m}^{2}$ (VIEIRA; FREITAS, 2007), o CT de excelência de Curitiba possui uma infraestrutura de alto nível. Segundo Carvalho (2007), o local é constituído por:

equipamentos oficiais e auxiliares distribuídos em dois ginásios de sessenta por trinta e seis metros cada qual, e uma equipe multidisciplinar formada por treinadores especialistas nacionais e internacionais, médicos, fisioterapeutas, psicólogos, nutricionistas, coreógrafos e coordenadores que gerenciam as demandas das seleções permanentes de GA (p.25).

Além desta estrutura esportiva, as ginastas que cursavam o ensino fundamental e médio, atendiam às aulas no próprio CT com professores particulares, situação que possibilitava a continuidade dos estudos sem prejuízo dos treinos. Diferentemente, aquelas que cursavam o ensino superior eram beneficiadas com bolsas de estudo e frequentavam as aulas no período noturno.

A manutenção da infraestrutura física do CT, períodos de aclimatação e intercâmbios no exterior, os honorários da comissão técnica formada por treinadores brasileiros e estrangeiros, a manutenção das atletas e o pagamento da equipe multidisciplinar para oferecer suporte à equipe foram subsidiados com 
recursos da Lei Agnelo/Piva e do patrocinador oficial da CBG (OLIVEIRA, 2010). Além desse apoio, a CBG dispunha de recursos do Programa Solidariedade Olímpica do Comitê Olímpico Internacional (COI) que, de acordo com o $\underline{\mathrm{COB}}$ (2006b), custeou os salários do técnico chefe durante o período da sua permanência no Brasil.

\section{Procedimentos metodológicos}

Optamos pela pesquisa qualitativa para compreender, analisar e discutir o contexto do CT de Curitiba e a abordagem centralizada de treinamento da seleção permanente. Neste tipo de estudo o pesquisador torna-se um instrumento primordial da coleta e da análise dos dados e procura compreender o fenômeno segundo a perspectiva dos participantes do estudo (THOMAS; NELSON, 2002).

Para a coleta de dados, utilizamos a entrevista semiestruturada, pois esta valoriza a presença do investigador e oferece perspectivas para que os sujeitos alcancem a liberdade e a espontaneidade necessárias para o estudo, o que torna 0 processo de investigação enriquecedor (TRIVIÑOS, 1987). Esta técnica permite que perguntas previamente formuladas, no roteiro preestabelecido, possam ser substituídas dependendo dos resultados e das evidências que o pesquisador obtém ao longo do procedimento.

Para a seleção dos sujeitos, consultamos as federações estaduais a fim de identificar as instituições filiadas que participam, ativamente, nos torneios oficiais estaduais e nacionais nas categorias: pré-infantil, infantil, infanto-juvenil e juvenil.

Foram entrevistados 34 técnicos da GAF que estão distribuídos em 29 instituições. O recorte do estudo ficou restrito à região Sudeste e Sul do Brasil devido à representatividade destes locais no panorama nacional competitivo da modalidade. Os sujeitos estão apresentados pela abreviatura $T$ (técnico) seguida por uma numeração, recurso adotado para fins de organização.

Para o tratamento dos dados, utilizamos a análise de conteúdo (BARDIN, 2008) como técnica de organização e de redução das informações coletadas em campo. Seguindo os preceitos de Bardin (2008), a análise compreendeu três etapas: pré-análise, exploração do material e a inferência.

O projeto foi submetido e aprovado pelo Comitê de Ética da Escola de Educação Física e
Esporte da Universidade de São Paulo, Protocolo de Pesquisa n. 56 de 2006.

\section{Resultados e discussão ${ }^{2}$}

O questionamento sobre o CT e a seleção permanente concentrada em Curitiba, permitiunos identificar aspectos positivos sobre a estrutura física e humana disponível para as atletas, conforme mostra o Quadro 2.

Ao refletir sobre a realidade brasileira, o indivíduo T7 cita que as instalações de Curitiba representam uma nova fase da modalidade no país, o que foi corroborado pelo depoimento de T29A que explicita que, no Brasil, não há melhor estrutura de trabalho. T3 afirma que o CT possui as melhores instalações para a prática da modalidade no país, opinião que é confirmada por T10A que considera a estrutura fenomenal. Vieira e Freitas (2007) citam que o centro oferece uma ampla estrutura de atendimento com o objetivo de suprir as mais diversas necessidades dos atletas. E, De Bosscher et al. (2009) confirmam que a infraestrutura de treinamento é um do pilares para o sucesso no esporte.

Esta nova fase da GA brasileira, citada por T7, refere-se às mudanças organizacionais sofridas pela modalidade durante a década de 90 e que culminaram com a construção do CT e o estabelecimento da antiga sede administrativa da CBG em Curitiba.

Smoleuskiy e Gaverdouskiy (1996) chamam a atenção para a importância da infraestrutura física na formação dos atletas da GA. Os autores afirmam que "este factor es el más vital" (p.22) na formação dos ginastas na atualidade. Fica claro que, sem as condições ideais de treinamento, as possibilidades de sucesso são prejudicadas e restritas ou improváveis. O técnico T2 corrobora com este pensamento ao dizer que a qualidade da infraestrutura disponível para o treinamento contribui com o desenvolvimento de um bom atleta. Além dos aparelhos modernos, que devem estar de acordo com as mudanças tecnológicas atuais, os ginastas necessitam de um suporte estrutural que abrange equipamentos auxiliares e colchões diferenciados para objetivos distintos.

Segundo Arkaev e Suchilin (2004), os requisitos básicos para equipar um ginásio de $\mathrm{GA}$

\footnotetext{
${ }^{2}$ Optamos por fazer uma transcrição direta dos depoimentos, sem quaisquer correções e interferências. Assim, por se tratar de discursos orais, não houve, por parte dos interlocutores, preocupação com estilo e adequação gramatical. Esclarecemos que a transcrição direta dos depoimentos foi uma opção, pois desejávamos maior fidelidade aos discursos produzidos e que não faremos o uso repetido e insistente de "sic" após os mesmos.
} 
consistem em assegurar as condições necessárias e mínimas para a segurança e a evolução dos ginastas. A estrutura física do CT de Curitiba teve um papel importante nos resultados obtidos pela GAF nos últimos dois ciclos Olímpicos, pois assegurou às ginastas aparelhos e equipamentos auxiliares dentro dos padrões internacionais. Esta condição contribuiu para a rápida evolução técnica, física e, também, psicológica, pois a qualidade dos equipamentos forneceu maior segurança no aprendizado e na execução dos elementos de risco e de dificuldade.

A importância atribuída ao corpo técnico, com a vinda dos técnicos estrangeiros ao país, pôde ser constatada no depoimento dos sujeitos que citaram o conhecimento e a experiência internacional dos treinadores como fatores fundamentais para os resultados obtidos pelo projeto implementado pela CBG. Na opinião de De Bosscher et al. (2009), a presença de técnicos experientes e que estão inseridos na elite internacional contribui para o sucesso esportivo de uma nação.

No discurso de T10A foi mencionada a equipe multidisciplinar que, em conjunto com a comissão técnica, constituem a infraestrutura humana disponível aos atletas no CT de Curitiba. Médicos, fisioterapeutas, psicólogos, nutricionistas e profissionais que atuam na organização e administração do centro podem ser enunciados como catalisadores do sucesso dos resultados adquiridos no decorrer de dois ciclos Olímpicos.

Quadro 2. Aspectos positivos acerca da infraestrutura física e humana do CT de Curitiba.

\begin{tabular}{|c|c|}
\hline Categoria & Unidade de análise \\
\hline $\begin{array}{c}\text { Infraestrutura } \\
\text { física e humana } \\
\text { do CT de Curitiba }\end{array}$ & 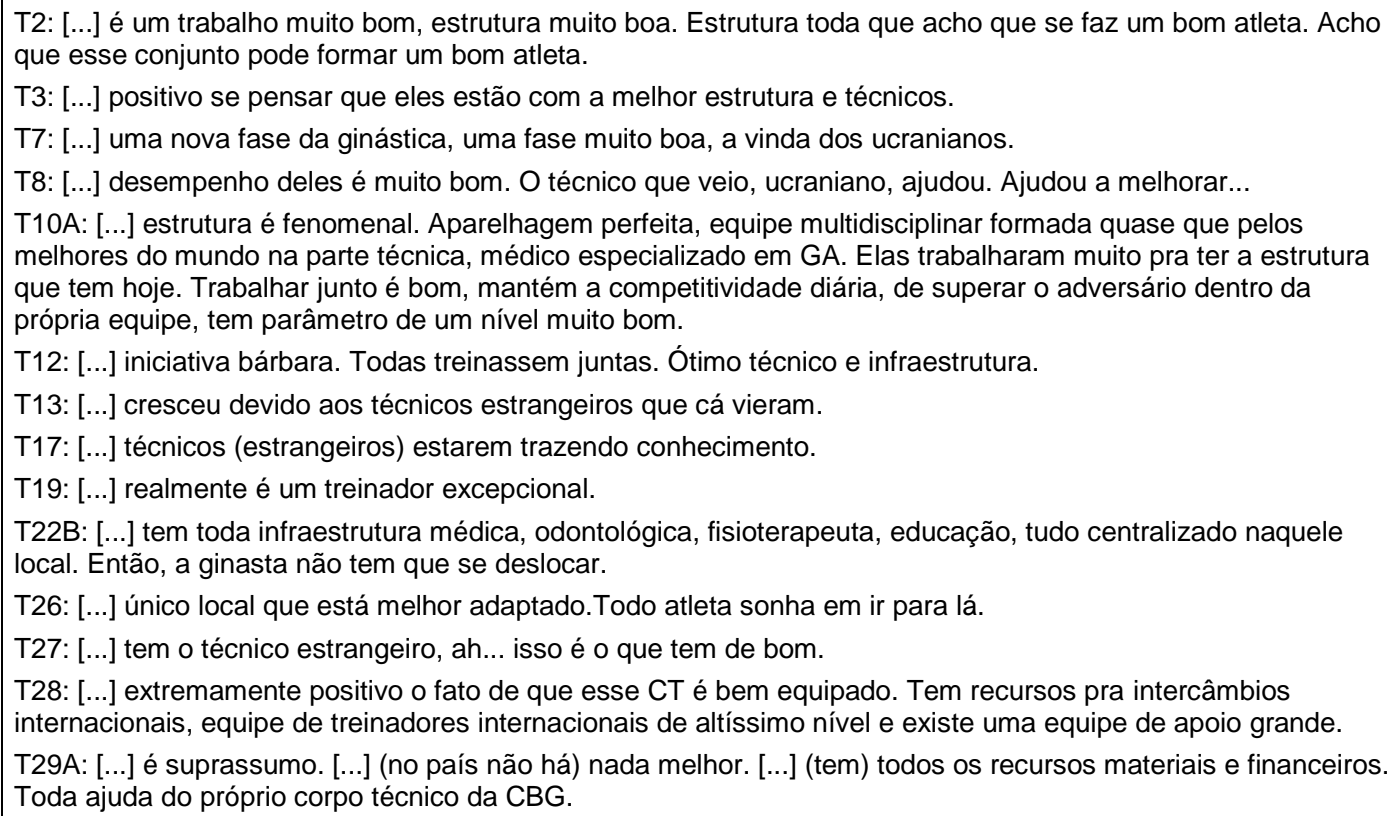 \\
\hline
\end{tabular}

Além da infraestrutura física e humana disponibilizada no CT, outro aspecto positivo, comentado pelos sujeitos, está relacionado ao apoio financeiro (Quadro 3) que, segundo De Bosscher et al. (2009), sustenta a política esportiva que influencia, em grande medida, o sucesso de um país no alto rendimento.

A partir de 2002, a ginástica brasileira passou a receber recursos da Lei Agnelo/Piva que, segundo Georgete Vidor, ex-técnica da seleção brasileira e atual coordenadora da GAF do Brasil, foi a grande responsável pelo desenvolvimento da modalidade no país (OLIVEIRA, 2010). Ainda de acordo com este autor, a conquista de um patrocinador oficial para a CBG também contribuiu para melhorar as condições das atletas e do CT. Além deste montante advindo de recursos públicos, a entidade obteve o apoio do Programa Solidariedade Olímpica que custeou o salário do técnico chefe. 
Quadro 3. Apoio financeiro.

\begin{tabular}{|c|l|}
\hline Categoria & \multicolumn{1}{c|}{ Unidade de análise } \\
\hline & $\begin{array}{l}\text { T2: [...] mudou muito esse negócio de seleção. As ginastas ganham para estarem lá. Tem toda uma estrutura. } \\
\text { T26: [...] melhorou para o alto nível, porque a mídia está investindo, os empresários estão investindo. [...] mais fácil } \\
\text { conseguir patrocínio, você tem uma ajuda de custo do COB. } \\
\text { T28: A preocupação em motivar os órgãos públicos a comprar sets de equipamentos que é um grande problema } \\
\text { que tem. Os equipamentos são caríssimos [...]. }\end{array}$ \\
\hline
\end{tabular}

O sujeito T28 cita a construção de núcleos de treinamento de base, em diferentes regiões do país, que foram subsidiados com o repasse financeiro do patrocinador da entidade. Embora estes centros tenham recebido a denominação de Centros de Excelência, comparativamente, a infraestrutura não condiz com a nomenclatura (OLIVEIRA, 2010).

Além dos recursos supracitados, a GAF recebeu o apoio do Programa Bolsa Atleta e da Lei de Incentivo ao Esporte. Ademais, o poder público possibilitou a aquisição de sets de aparelhos importados com isenção de impostos, aspecto que facilitou 0 acesso aos aparelhos homologados pela Federação Internacional de Ginástica (FIG). De acordo com Oliveira e Bortoleto (2011), são poucos os clubes que possuem recursos para adquirir os aparelhos importados e nenhuma empresa brasileira possui a homologação da FIG, aspecto que também prejudica o desenvolvimento da GA brasileira.

Embora o sujeito T26 tenha citado que houve um investimento financeiro da mídia, não foi constatada nenhuma renda significativa advinda deste setor para a CBG, diferentemente de outros esportes, como exemplo, 0 voleibol. Resguardadas as diferenças, a Confederação Brasileira de Voleibol (CBV) recebeu, no ano de 2009 , o montante de $R \$ 1.788 .747,00$ pela venda de direitos de transmissão dos jogos ( $\mathrm{CBV}, 2010)$. Para a GA, a contribuição dos veículos de comunicação ficou restrita, em grande medida, à popularização da modalidade, pois, possivelmente atraiu um maior contingente de praticantes. Mas, acreditamos que a CBG deveria utilizar a mídia de forma mais efetiva para atrair patrocinadores e recursos com a venda dos direitos de imagem, por exemplo.

Acerca da possibilidade das ginastas infantis e juvenis integrarem a seleção permanente, os sujeitos da pesquisa compreendem isso como uma experiência única e privilegiada devido à qualidade do CT e, também, pela presença de técnicos experientes e reconhecidos internacionalmente. O objetivo de fazer parte da equipe concentrada em Curitiba é visto como um fator de motivação e de dedicação para as atletas mais jovens, conforme podemos observar na fala de T5: "pode ser que ela se esforce cada vez mais, treine cada vez mais, se dedique cada vez mais com o objetivo de chegar à seleção". A busca da autorrealização, da superação dos desafios da prática e das competições reflete a motivação intrínseca das jovens ginastas que é determinante para o sucesso esportivo (LOPES; NUNOMURA, 2007).

Os resultados competitivos obtidos pela seleção permanente proporcionaram ao Brasil o reconhecimento e o respeito da comunidade esportiva nacional e internacional (Quadro 4). Segundo o sujeito T24, os resultados são positivos e incontestáveis e, na opinião de T17, representam um momento ótimo da modalidade no país.

$\mathrm{Na}$ visão de T16, este incremento dos resultados só foi possível graças ao sistema de trabalho centralizado e devido à infraestrutura física e humana disponível no CT.

Como podemos observar no Quadro 4, a imagem da GAF brasileira mudou e este reconhecimento não seria possível sem 0 aprimoramento técnico equitativo da equipe e, tampouco, sem os resultados internacionais. No discurso dos sujeitos verificamos que, além do reconhecimento e do respeito conquistados, houve um aumento de investimento na modalidade, conforme citado anteriormente, o que possibilitou o boom mencionado pelo sujeito T17.

A dificuldade em participar de eventos internacionais, no período que antecedeu a Lei Agnelo/Piva e a vinda de um patrocinador oficial para a CBG, surge no discurso de T27. O sujeito cita que agora "estamos participando de competições fora", pois, no período anterior a 2002, as ginastas tinham dificuldades de participar em eventos internacionais, como: as etapas de copa do mundo e até mesmo nos campeonatos mundiais (OLIVEIRA; BORTOLETO, 2009). Com o maior apoio 
financeiro, nossos ginastas aumentaram o número de participações em eventos no exterior. Este aspecto propiciou uma maior experiência competitiva dos atletas e possibilitou a conquista de bons resultados que, consequentemente, contribuíram para a mudança da imagem deste esporte no país e na comunidade mundial da GA.

Quadro 4. Melhora nos resultados competitivos e na imagem da GA feminina brasileira.

\begin{tabular}{|c|c|}
\hline Categoria & Unidade de análise \\
\hline Resultados & 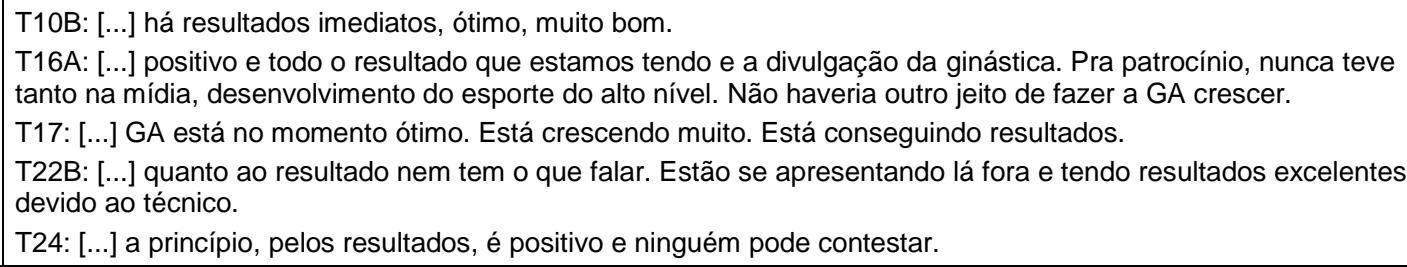 \\
\hline $\begin{array}{c}\text { Imagem da GA } \\
\text { feminina } \\
\text { brasileira }\end{array}$ & 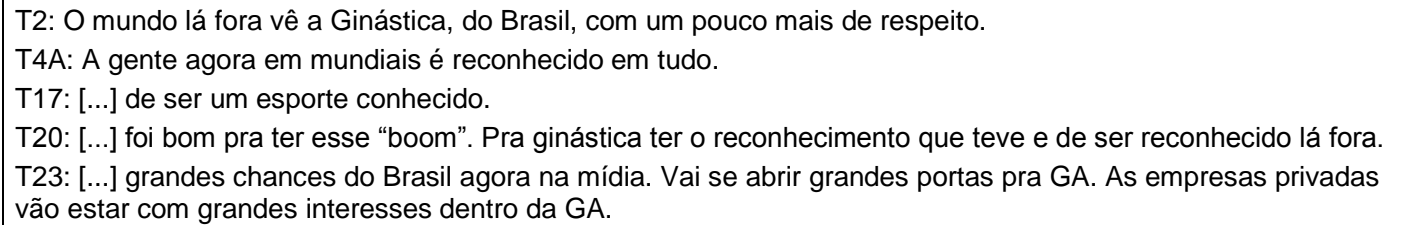 \\
\hline
\end{tabular}

Ao analisar a mídia estrangeira, observamos que os brasileiros conquistaram o respeito no panorama internacional da modalidade. As ginastas brasileiras estamparam a capa da revista International Gymnast, publicada nos EUA, em três ocasiões ${ }^{3}$ (fevereiro/2005, março/2007 e dezembro/2007) durante o período de vigência da seleção permanente concentrada, o que demonstra a sua projeção no mundo da ginástica.

Devemos analisar o sucesso competitivo conquistado pela GAF no panorama mundial com cautela, assim como os aspectos positivos enunciados pelos sujeitos. $O$ fato de a seleção obter resultados expressivos, com um melhor nível técnico não significa, necessariamente, um desenvolvimento equitativo desse esporte no Brasil. Ao longo do estudo constatamos, também, aspectos desfavoráveis deste sistema de trabalho reportado pelos técnicos e que serão abordados na sequência.

O monopólio das melhores ginastas do país, através da centralização no CT de Curitiba, foi um dos aspectos negativos que emergiu em alguns depoimentos, conforme observamos no Quadro 5.

De acordo com os técnicos, um país com as dimensões do Brasil necessita de vários pólos de treinamento que atendam às diferentes regiões. Esta ausência de CT nos estados, principalmente, naqueles com tradição na modalidade também foi citado como um ponto negativo deste sistema

\footnotetext{
${ }^{3}$ Não contabilizamos a capa da revista de fevereiro/2002, pois a atleta Daniele Hypólito não estava inserida no regime de concentração da seleção permanente.
}

centralizado em Curitiba devido ao deslocamento das ginastas para outra região.

Essa polarização da modalidade gerou outro problema que, segundo os técnicos, culminou com prejuízos às instituições que desenvolviam a modalidade no Brasil (Quadro 6).

Com a convocação das melhores ginastas para a seleção permanente, as instituições se enfraqueceram, pois perderam suas referências para as futuras gerações. Os técnicos se viram obrigados a enviar suas atletas, mesmo sendo prejudicados, pois, se estas permanecessem nos clubes, ficariam estagnadas frente àquelas que estivessem dentro do regime de treinamento permanente, apoiadas por uma equipe multidisciplinar e com a oferta de equipamentos de melhor qualidade. Este problema também afetou a representatividade dos estados nos eventos nacionais. Segundo o técnico T10A, a seleção estava ótima, mas, o restante do país não teve condições de acompanhar o mesmo grau de desenvolvimento.

Com a perda dessas atletas, os clubes e os treinadores se sentiram desmotivados para trabalhar com a modalidade visando ao alto rendimento, pois ficaram restritos ao desenvolvimento das categorias de base e de formação. O depoimento de T28 explicita o fato: "até que ponto, instituições privadas vão se interessar em patrocinar os custos que são relativamente altos da ginástica, para construir uma ginasta de alto nível, se em determinado momento essa ginasta não estará mais lá". Conforme o técnico $\mathrm{T} 19$, a política estabelecida 
pela CBG "acaba com o trabalho, mesmo que simples, de pequenas prefeituras, clubes, academias. Mata o processo de base, de formação, de iniciação" devido à desvalorização das instituições e dos profissionais que formam as ginastas.

Quadro 5. Aspectos desfavoráveis da centralização da equipe no CT de Curitiba.

\begin{tabular}{|c|c|}
\hline Categoria & Unidade de análise \\
\hline $\begin{array}{c}\text { Sistema } \\
\text { monopolizador e } \\
\text { Centralizador }\end{array}$ & $\begin{array}{l}\text { T3: [...] vai ser muito polarizado. } \\
\text { T4A: Eles se fecharam e pela confusão não temos abertura pra ir pra lá. } \\
\text { T5: [...] deveria ter mais CT. } \\
\text { T9: Ao invés de rodar as crianças rodar o treinador, seria muito melhor. Além de puxar as atletas ia } \\
\text { puxar os técnicos. [...] O técnico acha que aquilo é circulo fechado e não vai entrar nunca. Meio } \\
\text { utópico. } \\
\text { T10B: [...] sem contar que um país do tamanho do nosso é impossível ter um CT. Deveriam ter vários. } \\
\text { Não adianta ter vários atletas e treiná-los e depois deixar os treinadores e os clubes. } \\
\text { T12: Deveria ser criado um CT em SP, pois muitas são deslocadas. } \\
\text { T14: Seria interessante que esse pólo não fosse isolado. Se esse trabalhão fosse mais amplo e } \\
\text { divulgado poderíamos galgar caminhos melhores. } \\
\text { T15: Aquilo é poder centralizador, não aceita difundir. O papel de CBG é difundir o esporte no país } \\
\text { inteiro e não só em um local e centralizar. O maior pólo de ginástica hoje é SP, tem o maior número de } \\
\text { ginastas praticantes aqui. } \\
\text { T15: [...] focalizem mais os estados que têm GA. Pólos onde têm GA e criem CTs nestes estados. } \\
\text { T18: [...] negativo é que tem poucos CTs. } \\
\text { T19: A idéia era formar CT de GA no Brasil, seis ou sete, e dividiria bem regionalmente. } \\
\text { T20: Deveria existir mais CTs, mas é aquela coisa centralizadora. } \\
\text { T22B: [...] se em todos os estados do Brasil houvesse isso, a GA ia evoluir mais. } \\
\text { T23: Eles colocam muito a importância de um único centro, mas o Brasil é muito grande, tem muita } \\
\text { gente boa. } \\
\text { T28: [...] criar núcleos, vários núcleos, com CT em vários lugares. } \\
\text { T29B: O Centro é centralizado... acho que precisa mais, mais centros. Já se provou que dá certo, que... } \\
\text { eu acho que agora eles deveriam abrir, divulgar... }\end{array}$ \\
\hline
\end{tabular}

Quadro 6. Implicações às instituições que desenvolvem a GA feminina.

\begin{tabular}{|c|c|}
\hline Cate & Unidade de análise \\
\hline $\begin{array}{l}\text { Prej } \\
\text { Insti }\end{array}$ & 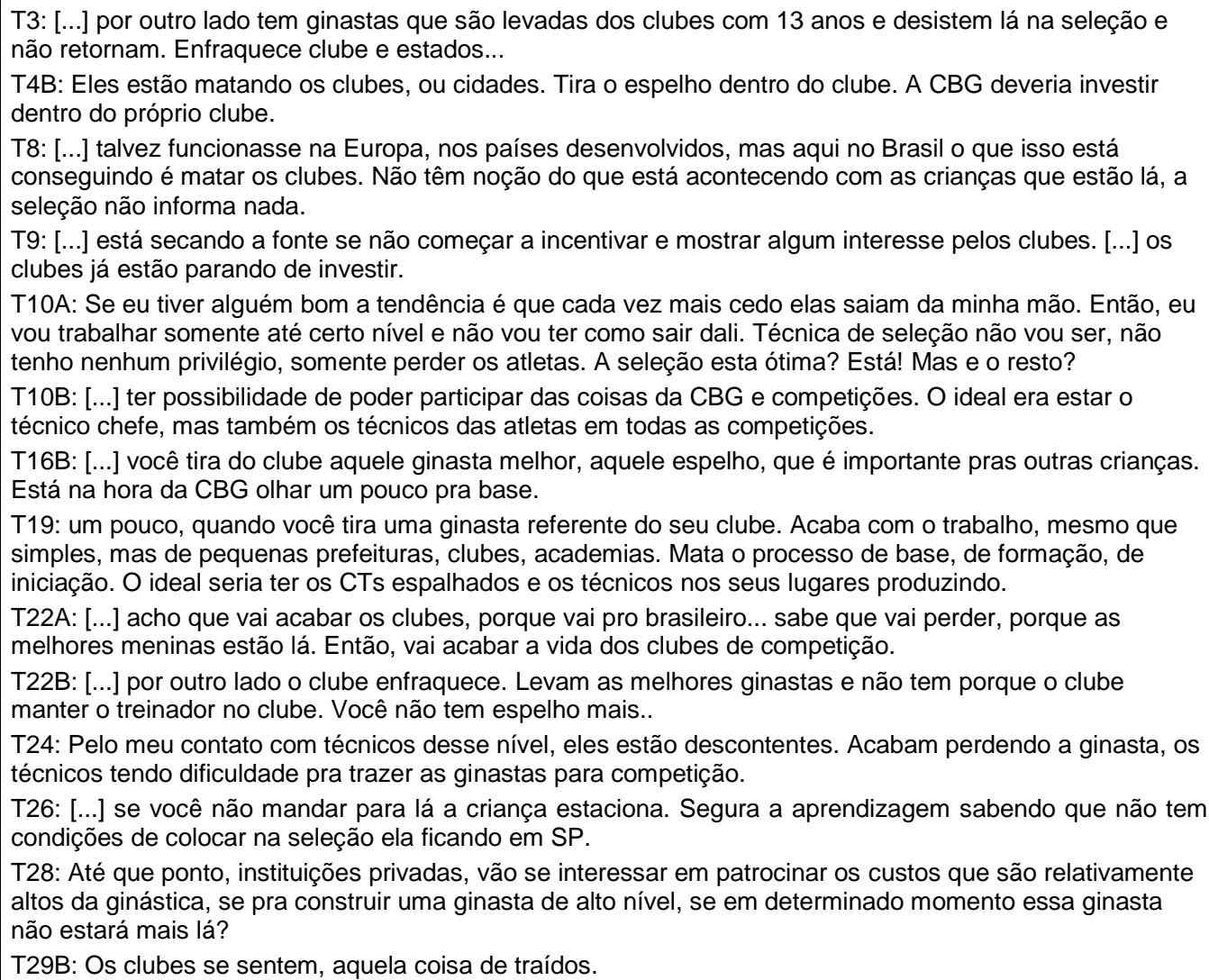 \\
\hline
\end{tabular}


No Quadro 7 podemos acompanhar os aspectos negativos da desvalorização e da falta de reconhecimento dos treinadores no país durante o período da seleção permanente concentrada em Curitiba.

Quadro 7. Desvalorização ou falta de reconhecimento do treinador brasileiro.

\begin{tabular}{|c|c|}
\hline Categoria & Unidade de análise \\
\hline $\begin{array}{l}\text { Desvalorização } \\
\text { ou falta de } \\
\text { reconhecimento } \\
\text { do técnico } \\
\text { brasileiro }\end{array}$ & 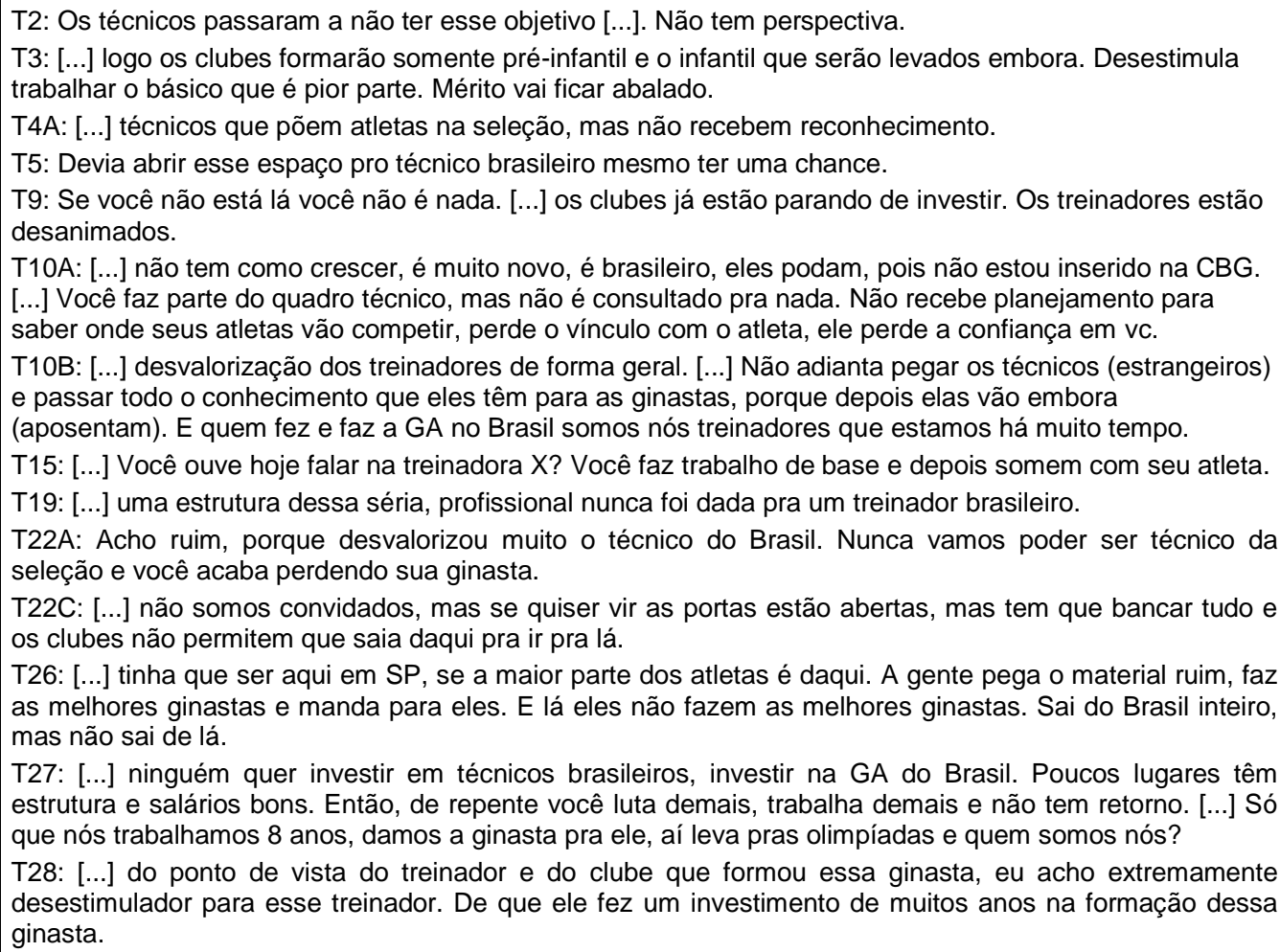 \\
\hline
\end{tabular}

De acordo com as informações contidas no Quadro 7, verificamos a insatisfação dos treinadores que desenvolveram as ginastas, que foram selecionadas para compor a equipe nacional e não receberam incentivo ou reconhecimento por parte da CBG. O discurso de T26 resume o sentimento de frustração dos técnicos formadores das atletas que estiveram em Curitiba ao longo da vigência da seleção permanente concentrada: "[...] nós trabalhamos 8 anos, damos a ginasta para ele (referindo-se ao técnico da seleção). Aí ele leva para as olimpíadas e quem somos nós?". Segundo o técnico T28, "do ponto de vista do treinador e do clube que formou essa ginasta, eu acho extremamente desestimulador pra esse treinador, de que ele fez um investimento de muitos anos na formação dessa ginasta".

Os sujeitos citam as dificuldades pelas quais passaram para formar as atletas e a falta de perspectiva em trabalhar no alto nível, pois pouquíssimos técnicos brasileiros compuseram o corpo técnico ao lado dos técnicos estrangeiros.
Salários baixos, falta de infraestrutura e a restrição ao trabalho de base e de formação são alguns fatores citados como negativos por muitos treinadores que não visualizam perspectivas de avançar na carreira de técnico com a vigência deste sistema centralizado de treinamento.

Corroboramos com o sujeito $\mathrm{T} 10 \mathrm{~B}$ ao afirmar que a CBG deveria valorizar e investir no técnico nacional, pois "Não adianta pegar os técnicos (estrangeiros) e passar todo o conhecimento que eles têm pras ginastas, porque depois eles vão embora. E, quem fez e faz a GA no Brasil somos nós treinadores [...]".

Outro problema é a perda de vínculo entre o técnico e a ginasta que está na seleção: "Você faz parte do quadro técnico, mas não é consultado para nada, não recebe planejamento para saber onde seus atletas vão competir, perde o vínculo com o atleta, ele perde a confiança em você [...]" (T10A).

$\mathrm{Na}$ visão de alguns sujeitos, a CBG não optou pelo investimento nos profissionais brasileiros $\mathrm{e}$ 
deixou de valorizar aqueles que já desenvolviam atletas de alto rendimento no país, mesmo com todas as dificuldades financeiras $e$ de infraestrutura (Quadro 8).

Quadro 8. Aspectos negativos da falta de apoio à formação dos profissionais da GA.

\begin{tabular}{|c|l|}
\hline Categoria & \multicolumn{1}{c|}{ Unidade de análise } \\
\hline \multirow{5}{*}{ Formação } & $\begin{array}{l}\text { T3: }[\ldots] \text { poderiam formar técnicos fora do CT. Não dão oportunidade de aprender. } \\
\text { T4A: }[\ldots] \text { não estão trazendo curso como prometeram. } \\
\text { T5: Acho que devia ter um espaço a mais, dentro da CBG mesmo, e sempre esses estrangeiros estarem } \\
\text { fazendo cursos. } \\
\text { T9: Não sou contra a seleção permanente não. Só acho que tinha de ser um pouco mais flexível, mas acho } \\
\text { que tem que dar oportunidade aos técnicos. Só um. Desde 99 e só deu } 1 \text { curso. Não tem interesse. Os caras } \\
\text { não querem. Não querem ajudar nada. Querem ficar lá e acabou. É mais seguro. } \\
\text { T10B: Falar que a CBG esta aberta é uma utopia. Como vou sair daqui e ir pra lá olhando pra aprender? É } \\
\text { uma mentira. } \\
\text { T13: Critico muito, porque deveria ser aberto pra gente fazer curso, aberto pros técnicos do interior. } \\
\text { T16B: Tecnicamente deveriam criar oportunidades para os técnicos nacionais desenvolverem-se. }\end{array}$ \\
$\begin{array}{l}\text { T20: CBG poderia promover cursos com os estrangeiros que são pessoas que sabem tanto. [...] tem que } \\
\text { pensar que a gente tem que especializar mais técnicos. } \\
\text { T22C: mas os técnicos deveriam rodar nos clubes, porque a gente está aprendendo muito pouco, se você } \\
\text { não vai lá não aprende. } \\
\text { T26: Falam que vão fazer a Escola Brasileira (de Ginástica), mas não existe Escola Brasileira (de Ginástica). } \\
\text { T29B: Eles não fazem cursos, de estarem muito empenhados com a seleção. }\end{array}$ \\
\hline
\end{tabular}

Os técnicos afirmam que não ocorreu um processo contínuo de cursos organizados pela CBG que pudessem promover a formação dos técnicos nacionais. Apenas os técnicos que trabalhavam no CT em Curitiba puderam aprender com os treinadores estrangeiros que, de acordo com T9, realizaram apenas um curso no ano de 1999. Na visão de T16B, "tecnicamente deveriam criar oportunidades para os técnicos nacionais desenvolverem-se". Nunomura (2004) afirma que os técnicos possuem a necessidade de uma formação continuada, pois, à medida que os seus ginastas evoluem eles precisam ampliar o seu conhecimento e, o oferecimento de cursos específicos, permitiria que estes profissionais prosseguissem e se aprimorassem na carreira.

Os treinadores acreditam que não houve apenas a desvalorização do técnico, mas também da ginasta, pois o sistema centralizado gerou prejuízos a algumas atletas que compuseram a equipe (Quadro 9).

Quadro 9. Implicações às ginastas que compuseram a seleção permanente concentrada em Curitiba.

\begin{tabular}{|c|l|}
\hline Categoria & \multicolumn{1}{c|}{ Unidade de análise } \\
\hline & $\begin{array}{l}\text { T2: Não vê a criança. Vê a ginasta. Vê uma peça-chave para compor. É muito descartável. Porque que vou } \\
\text { me preocupar com você se tenho 10 e ponho outra no seu lugar? [...] a ginasta voltou até com problema de } \\
\text { depressão, não saía de casa. }\end{array}$ \\
$\begin{array}{l}\text { T12: Deveria ser criado um CT em SP, pois muitas são deslocadas. } \\
\text { Distúrbios e } \\
\text { prejuízos às } \\
\text { ginastas }\end{array}$ & $\begin{array}{l}\text { Não tem matícil a menina de 14/15 anos e tirar de casa e levar pra longe e falar pra ela vai morar longe dos pais. } \\
\text { T19: [...] ginastas de nível bom que ficaram perdidas no ar. } \\
\text { T20: [...] meninas de 12 anos que têm de abandonar a família e a região que moram e todos os conhecidos } \\
\text { e ficarem sozinhas e isoladas. } \\
\text { T28: [...] tira do seio da família a ginasta muito jovem. [...] submetida à rotina de treinamento extenuante e } \\
\text { controle alimentar rigoroso, sem ter o afeto da família, tão jovem! Então, eu acho isso muito complicado. }\end{array}$ \\
\hline
\end{tabular}

Polêmicas sobre o controle alimentar e a rotina extenuante de treinamento imposto às ginastas, estiveram no holofote da mídia nacional após os Jogos Olímpicos de 2008 e foram discutidas nos diferentes veículos de informação.

Algumas ex-ginastas da seleção permanente relataram problemas na assistência médica e overtraining ocorridos no CT durante o período em que serviram à equipe permanente concentrada. Alguns desses aspectos foram veiculados pela ESPN Brasil no programa "Histórias do Esporte: sem limites" (2008), no qual as atletas descreveram um pouco da sua rotina 
em Curitiba e abordaram situações vividas dentro e fora do ginásio.

Nunomura (2008, p.77) aponta que "os ginastas profissionais praticam, normalmente, de quatro a sete horas por dia, até seis dias por semana" e nos períodos que antecedem as competições os ginastas treinam até mesmo aos domingos e possuem de 15 a 20 dias de férias por ano. Ainda de acordo com a autora, "os ginastas admitem que há sacrifícios" (p.78), dentre eles: os horários rígidos, dietas rigorosas e pouco tempo para a família, o lazer, a escola e qualquer outra atividade. Este sacrifício emerge no discurso do técnico T2: "Por fora é muito bonito, a gente vê aquelas meninas maravilhosas, mas você vai acompanhar o dia-a-dia do ginásio, não é bem assim". Parte da rotina de treinamento das atletas da seleção pode ser acompanhada no documentário Travessia do $\operatorname{Ar}$ (2004).

Na opinião do técnico T2, a origem humilde da maior parte das atletas pode ter contribuído com a conivência dos pais e das próprias atletas às condições postas no período em que estiveram concentradas no CT de Curitiba: "Os pais até perdem um pouco desse valor. Acho que virou até mercado um pouco também, não querem saber se está sofrendo, está ganhando quanto por mês? [...] eu acho que virou um pouco mercadoria. [...] estão tentando segurar com dinheiro, alguma projeção" (T2).

O deslocamento das atletas para outra cidade, onde foram submetidas às diferenças climáticas, culturais e à distância da família, também, foi considerado um dos fatores prejudiciais para as ginastas.

Muitas atletas que não se adaptaram ao sistema de treinamento imposto no CT em Curitiba abandonaram a modalidade ao retornarem aos seus clubes de origem. Outras meninas que não foram selecionadas tiveram o mesmo destino, o que ocasionou a diminuição do número de atletas atuantes no país (Quadro 10). Esta falta de perspectiva para avançar na carreira esportiva poderia explicar a falta de motivação e o drop-out das atletas (LOPES; NUNOMURA, 2007).

Quadro 10. Aspectos relativos à desistência e à desmotivação das ginastas.

\begin{tabular}{|c|c|}
\hline Categoria & Unidade de análise \\
\hline $\begin{array}{l}\text { Desistência e } \\
\text { desmotivação } \\
\text { das ginastas }\end{array}$ & $\begin{array}{l}\text { T2: [...] mudar um pouquinho nesse lado de segurar as ginastas. Não sei se esta é a palavra de como manter } \\
\text { ela mais tempo. Para cedo. É aquela coisa, parou, não quer saber mais. Brasil não tem essa história. } 17 \\
\text { (anos), tchau, acabou. } \\
\text { T4B: A criança tem que viver a GA. Se elas não estão indo para brasileiro e saindo para competir, elas têm } \\
\text { uma visão diferente daquelas que fazem isso. } \\
\text { T8: [...] é quem treina nos clubes ou treinam já sem aspiração nenhuma de pegar seleção. Eles sabem que } \\
\text { quem vai viajar é só as que estão lá. É frustrante! } \\
\text { T10A: Hoje têm poucos trabalhando pra rendimento. Umas } 4 \text { equipes no Brasil inteiro. Tem atleta que nunca } \\
\text { vai competir fora, porque não tem nem seletiva. } \\
\text { T11: Hoje não tem mais categorias de base. O que vai sobrar lá pra cima? Tinha que fazer um trabalho em } \\
\text { cima disso. Chamar mais crianças, mais profissionais, mais clubes. } \\
\text { T20: Acho péssimo e, inclusive, por isso que acho que tem que ter mais CTs, porque uma menina que não } \\
\text { pega a seleção, elas tendem até a parar a ginástica. Limita muito o número de meninas praticando. Porque é } \\
\text { a expectativa. Não tem. } \\
\text { T22B: Nossas ginastas sempre tentam seleção. Tiveram apoio do clube pra isso. Tem o investimento e } \\
\text { gasto. Já sabíamos que seria difícil entrar. Fica mais difícil o ingresso na seleção. } \\
\text { T22C: [...] se ela volta ela desiste. Acabou a equipe pras competições. Você não vai ter mais atletas pra } \\
\text { treinar. Vai estar sempre começando de novo. } \\
\text { T28: [...] também desmotivação por parte das crianças ou uma menor motivação por parte da criança que } \\
\text { (ela) teria se aquelas grandes ginastas tivessem treinando ali junto. }\end{array}$ \\
\hline
\end{tabular}

O técnico T2 afirma que, no Brasil, ainda permanece a cultura de que as ginastas devem encerrar a sua carreira na adolescência, contrariando a tendência mundial na qual as atletas vêm ampliando a longevidade na GA devido à possibilidade de competir como especialistas de provas e, também, aos avanços tecnológicos nos aparelhos e métodos de treinamento.
Outro aspecto que teria contribuído para a desmotivação e, a consequente desistência das atletas, relaciona-se ao fato de que apenas as ginastas que estavam na equipe brasileira permanente tinham a oportunidade de viajar para os campeonatos internacionais representando o Brasil. De acordo com o técnico T10A: "Hoje têm poucos trabalhando pra rendimento. Umas 4 equipes no Brasil inteiro. Tem atleta que nunca 
vai competir fora (do país), porque não tem nem seletiva". No estudo elaborado por Lopes e Nunomura (2007), as autoras citam que $25 \%$ das ginastas têm 0 interesse em treinar enquanto tiverem boas oportunidades para competir. Isso demonstra a importância que a competição tem no processo de treinamento e para a manutenção no esporte.

No Quadro 10 podemos observar, também, que a saída das atletas para a seleção prejudicou o trabalho com as meninas que estavam em formação, pois estas perderam um referencial importante dentro da microcultura do ginásio. A ausência desses ícones no clube contribuiu para a diminuição no número de atletas que não têm um exemplo de sucesso a ser seguido. O técnico T11 resume esta problemática ao relatar que: "Hoje não tem mais categorias de base, o que vai sobrar lá pra cima? Tinha que fazer um trabalho em cima disso, chamar mais crianças, mais profissionais, mais clubes". A necessidade de ter um referencial no ginásio, um ídolo, se faz necessária, pois este modelo de sucesso serve de projeção para as demais atletas. Nas palavras de Morato, Giglio e Gomes (2011, p.9), "a construção da relação entre ídolo e admiradores é estabelecida, principalmente, por aqueles torcedores ou aprendizes que o viram jogar". Isso propicia um maior interesse e paixão pelo esporte e renova o sonho dos jovens esportistas em seguirem os passos do indivíduo admirado.

O declínio no número de equipes e ginastas atuantes no país pode ser reflexo direto da política implantada pela CBG nos últimos ciclos Olímpicos. Segundo o técnico T15, "Tudo que eles decidem lá afeta a gente".

Alguns técnicos afirmam que faltaram incentivos na política da CBG para estimular a massificação da modalidade no país e que contribuíssem para o desenvolvimento equitativo da GAF no decorrer dos dois ciclos Olímpicos. $O$ técnico T22C cita que o CT deve existir, mas que o apoio aos clubes não pode ser negligenciado: "[...] deveria ter o centro, mas ele deveria dar suporte aos clubes, porque a gente está ficando, não é nem desmotivado". Este pensamento pode ter fundamento, pois os clubes investem e formam os ginastas que, no futuro, poderão atuar na seleção e eles precisam ser valorizados.

Os técnicos também relacionaram, entre os aspectos desfavoráveis, a não valorização da GA masculina. Segundo o técnico T9, houve maior preocupação com 0 desenvolvimento da categoria feminina: "pro feminino é melhor que masculino, porque a verba é pra elas, é tudo delas". O técnico T10A foi mais enfático em sua crítica: "[...] vê o preconceito, eles dão prioridade pro feminino. Por que não tem pré-equipe masculina? Ah! Porque o ginásio não comporta! Será? Vemos que não há preocupação de crescimento da GA no âmbito da modalidade".

\section{Considerações finais}

Houve um consenso, entre a maioria dos treinadores, de que ocorreu uma melhora da GAF, principalmente, no alto rendimento. Isso demonstra que os esforços da CBG lograram bons resultados e que estes merecem ser valorizados.

Os aspectos positivos relatados pelos técnicos relacionam-se à infraestrutura física e humana, aos recursos financeiros, à melhora na representatividade do país no panorama internacional, ao interesse da mídia e ao crescimento qualitativo dos resultados competitivos da modalidade nos últimos anos no alto rendimento. Mas, alguns problemas emergiram do discurso dos técnicos e são consideráveis, como pudemos constatar pelo volume de categorias que foram estabelecidas e as respectivas unidades de sentido.

Os técnicos afirmam que houve desvalorização e falta de reconhecimento do profissional brasileiro, pois, com a contratação dos técnicos estrangeiros, os brasileiros não visualizavam perspectivas de atuar na seleção como era a intenção de alguns deles. Outros acreditam que $o$ treinador nacional, que trabalha na formação da ginasta, deveria ser reconhecido e convidado a compor a comissão técnica, ao menos, para acompanhar alguns treinamentos e campeonatos. Eles relataram que depois que as ginastas foram deslocadas para o CT eles perderam o contato com as atletas e acreditam que a $C B G$ não fez esforços suficientes para manter este vínculo.

Segundo alguns técnicos, os treinadores nacionais não tiveram oportunidade de demonstrar o seu potencial, pois jamais tiveram à disposição uma infraestrutura semelhante à que a CBG proporcionou aos técnicos estrangeiros. Muitos acreditam que a entidade deveria ter oferecido aos técnicos brasileiros a possibilidade de aperfeiçoamento profissional aproveitando a estada dos técnicos estrangeiros. Eles afirmam 
que estavam muito interessados em aprender e se aprimorar, mas não perceberam iniciativas da CBG.

$\mathrm{Na}$ opinião de alguns sujeitos, o fato de retirar as melhores ginastas de suas instituições foi prejudicial, pois ocasionou a perda de um referencial importante para aqueles que estão ascendendo na modalidade. Esse fato dificultou a aderência das crianças, pois o "ídolo" não estava mais lá no clube e, também, a ginasta que era convocada para a seleção perdia o vínculo com a sua equipe de origem. Assim, todo o investimento da instituição e dos técnicos não tinha retorno.

Esse quadro desestimulou os clubes a investirem na GA e, consequentemente, prejudicou as demais ginastas, técnicos e a GAF em geral. Além disso, as ginastas que não obtiveram sucesso em ingressar na seleção desanimaram e, muitas, ficaram sem aspirações e perspectivas e acabaram desistindo. $O$ fato fragilizou ainda mais o processo de formação das futuras gerações de ginastas no país.

Alguns técnicos mencionaram que tudo se concentrou no CT, em Curitiba, e eles definiram a situação como um monopólio. Outros alegaram que o país é muito grande e é preciso despolarizar para que mais crianças e jovens tenham oportunidade de ingressar na seleção.

Outros aspectos desfavoráveis também foram levantados, por exemplo: o fato das ginastas serem retiradas do "seio da família" muito jovens; o dia-a-dia no CT não era "agradável"; e que "estão tentando segurar com dinheiro", foram algumas declarações que revelaram uma visão negativa do formato da seleção permanente concentrada.

Para os sujeitos está claro que a perspectiva para quem ingressava na seleção permanente era boa: bolsa de estudos, salário, assistência médica, moradia, prêmios, entre outros benefícios. Porém, a dúvida de muitos era se esses benefícios não poderiam ser compartilhados com mais ginastas que sonhavam em ser uma nova estrela da ginástica brasileira, como Daiane dos Santos.

A possibilidade de ampliar a idéia do CT em outros estados foi engavetada e, desde o final de 2008, a seleção permanente concentrada foi desativada e foi adotado um sistema descentralizado, mas, que ainda não obteve resultados satisfatórios ou comparáveis com aqueles adquiridos nos ciclos Olímpicos anteriores sob o modelo soviético de treinamento.

Alguns países de grande expressão na modalidade, como os Estados Unidos, também utilizam o sistema descentralizado. Entretanto, as atletas têm à sua disposição uma infraestrutura física e humana dentro dos padrões internacionais, diferente da realidade dos clubes brasileiros, o que dificulta o sucesso do sistema de seleção permanente vigente no Brasil.

Acreditamos que a experiência de criar um CT de excelência e uma seleção permanente concentrada proporcionou muito aprendizado para todos, seja para a CBG, o COB, os técnicos, as atletas, entre outros envolvidos.

A partir desta iniciativa e de seus respectivos resultados e repercussões, é importante refletir e repensar o formato e a concepção que geraram este projeto. Não há dúvidas de que este sistema de trabalho implementado foi efetivo para os objetivos propostos. Por outro lado, foram levantados questionamentos que alimentaram as discussões sobre 0 crescimento e o desenvolvimento da GAF no país. Os depoimentos podem servir de referência para as futuras ações dos órgãos que administram a modalidade no Brasil.

Estamos certos de que foi importante ousar, tentar e desafiar o incerto, ou seja, mesmo sem ter a certeza da qualidade dos frutos que se colheriam. Mas, como toda colheita, houve ganhos e perdas. Ainda assim, o semeador não deve desistir e, logo deverá preparar a terra para a próxima safra, com a expectativa de que os ganhos superem as perdas. $O$ grande aprendizado que foi colhido dessa experiência, sejam pontos positivos ou negativos, deve ser aproveitado para fundamentar futuros empreendimentos na modalidade.

\section{Referências}

ARKAEV, L.; SUCHILIN, N. Gymnastics: how to create champions. Oxford: Meyer \& Meyer Sport, 2004.

BARDIN, L. Análise de conteúdo. Lisboa: Edições 70, 2008.

CARVALHO, S. O discurso midiático da ginástica artística. 2007. 102 f. Dissertação (Mestrado em Educação Física) - Universidade Católica de Brasília, Brasília, 2007. 
COMITE OLÍMPICO BRASILEIRO (COB).

Ginástica artística do Brasil mostra a sua evolução ao mundo. Boletim Olímpico, Rio de Janeiro, v. 1, n. 3, 2003.

COMITE OLÍMPICO BRASILEIRO (COB). Centralizar para desenvolver. Boletim Olímpico, Rio de Janeiro, v. 4, n. 15, $2006 a$.

COMITE OLÍMPICO BRASILEIRO (COB). Diversidade e conhecimento a serviço do esporte brasileiro. Boletim Olímpico, Rio de Janeiro, v. 4, n. $14,2006 \mathrm{~b}$.

CONFEDERAÇÃO BRASILEIRA DE VOLEIBOL (CBV). Balanço financeiro. 2010. Disponível em: $<$ http://www.cbv.com.br/cbv2008/institucional/bala ncos/Bal CBV 2010.pdf>. Acesso em: 18 jul. 2010.

CONSELHO FEDERAL DE EDUCAÇÂO FÍSICA (CONFEF). A ginástica forma futuros técnicos de ouro. Revista E. F., Rio de Janeiro, n. 12, 2004.

DE BOSSCHER, V.; DE KNOP, P.; VAN BOTTENBURG, M.; SHIBLI, S.; BINGHAM, J. Explaining international sporting success: an international comparison of elite sport systems and policies in six countries. Sport Management Review, Sydney, v. 12, n. 3, p. 113-136, 2009.

ESCUELA de deportes: gimnasia artística feminina. Direção de Bernardino Lombao. Produção de CDP Comunicación, Deporte y Producciones. Madrid: TVE, 2001.

REPORTER special: gimnastele. Reportagem de Ioana Răduca. Romênia: Antena 3, 2008.

HISTÓRIAS do esporte: sem limites. Reportagem de Ronaldo Kotscho. Direção de José Trajano. Brasil: ESPN Brasil, 2008.

LOPES, P.; NUNOMURA, M. Motivação para a prática e permanência na ginástica artística de alto nível. Revista Brasileira de Educação Física e Esporte, São Paulo, v. 21, n. 3, p. 177187, 2007.

MORATO, M. P.; GIGLIO, S. S.; GOMES, M. S. $P$. A construção do ídolo no fenômeno futebol. Motriz. Revista de Educação Física. UNESP, Rio Claro, v. 17, n. 1, p. 01-10, 2011.

NUNOMURA, M. A formação dos técnicos de ginástica artística: os modelos internacionais. Revista Brasileira de Ciência e Movimento, Brasília, v. 12, n. 3, p. 63-69, 2004.

NUNOMURA, M. Ginástica artística. São Paulo: Odysseus, 2008.
OLIVEIRA, M. S.; BORTOLETO, M. A. C. A ginástica artística masculina brasileira no panorama mundial competitivo (1987-2008). Motriz. Revista de Educação Física. UNESP, Rio Claro, v. 15, n. 2, p. 297-309, 2009.

OLIVEIRA, M. S. O panorama da ginástica artística masculina brasileira: um estudo histórico-crítico do período 2005-2008. 2010. 256 f. Dissertação (Mestrado em Educação Física) Faculdade de Educação Física, Universidade Estadual de Campinas, Campinas, 2010.

OLIVEIRA, M. S.; BORTOLETO, M. A. C. Apontamentos sobre a evolução histórica, material e morfológica dos aparelhos da ginástica artística masculina. Revista da Educação Física/UEM, Maringá, v. 22, n. 2, p. 283-295, 2011.

SMOLEUSKIY, V.; GAVERDOUSKIY, I. Tratado general de gimnasia artística deportiva. Barcelona: Paidotribo, 1996.

SUEÑOS olimpicos (the red race). Direção de Chao Gan. Produção executiva de Qiming Ying. China: Shanghai double montage production company, 2008.

THE SECRET of deva. Direção de Anca Miruna Lazarescu. Produção de Adina Bouwer. Munique: Twinpix Filmproduktion, 2007.

THOMAS, J. R.; NELSON, J. K. Métodos de pesquisa em atividade física. 3 . ed. Porto Alegre: Artmed, 2002.

TRAVESSIA do ar. Direção de Dorrit Harazim. Produção de Raquel Zangrandi. Rio de Janeiro: Vídeo Filmes, 2004.

TRIVIÑOS, A. N. S. Introdução à pesquisa em Ciências Sociais: a pesquisa qualitativa em educação. São Paulo: Atlas, 1987.

VIEIRA, S.; FREITAS, A. O que e ginástica artística. Rio de Janeiro: Casa da Palavra, 2007.

Apoio: FAPESP.

Endereço:

Mauricio Santos Oliveira

Av. Dr. Moraes Sales, 1706/151, Centro

Campinas

CEP: 13010-002

e-mail: mauoliveira@usp.br 
Recebido em: 25 de novembro de 2010.

Aceito em: 28 de dezembro de 2011.

\section{(c) (7)}

Motriz. Revista de Educação Física. UNESP, Rio Claro, SP,

Brasil - elSSN: 1980-6574 - está licenciada sob Creative

Commons - Atribuição 3.0 